\title{
LIDERAZGO FEMENINO EN SITUACIONES DE EMERGENCIA. PANDEMIA COVID 19 EN PERÚ
}

\section{Female leadership in emergency situations. COVID 19 Pandemic in Peru}

\author{
Martha Llanos Zuloaga* \\ Exasesora Regional de Unicef - Lima, Perú \\ https://orcid.org/0000-0001-5456-1530
}

\begin{abstract}
Resumen
El tema del liderazgo femenino se hace cada vez más presente en las reflexiones y estudios de género. Actualmente hay muchas evidencias del enorme potencial de las mujeres para participar y aportar significativamente en la solución de conflictos y en las gestiones grupales por esa dimensión de liderazgo humanista que caracteriza a las mujeres.

El sistema patriarcal y el machismo hacen un frente común pero la demostrada capacidad de Resiliencia de las mujeres está cada vez más consolidada. Es principalmente en situaciones de emergencia y conflicto que ese liderazgo y resiliencia se manifiestan con un nivel de organización y solidaridad propia de las mujeres en situaciones de pobreza y vulnerabilidad. EL Covid 19 ha puesto de manifiesto muchos problemas institucionales, de sectores de visiones carentes de conocimiento de la realidad y otros, pero también ha destacado la respuesta solidaria, única y pronta de las mujeres. Como investigadora de Resiliencia, como testigo de grupos de mujeres en su rol de Educadoras, Promotoras, madres en los comedores, vasos de leche, PRONOEIS (programas no Escolarizados de Educación Inicial) y otros programas sociales comunitarios, comparo la experiencia peruana extendida en Latinoamérica de las Ollas Populares.
\end{abstract}

Palabras claves: liderazgo femenino. patriarcado. machismo. resiliencia. mujeres organizadas. liderazgo en pandemia. ollas comunes.

\begin{abstract}
The theme of female leadership is increasingly present in reflections and studies on gender. Currently, there is strong evidence of the vast potential of women to participate and make a significant contribution to conflict resolution and group management due to the humanistic leadership that characterizes women.

The patriarchal system and machismo make up a combined threat, but women's resilience has been demonstrated and consolidated. It is mainly in emergency and conflict situations that their leadership and resilience are demonstrated with a level of organization and solidarity typical of women in situations of limited vision and awareness of reality, among other problems, but it has also highlighted women's solidarity and prompt response.

From my experience as a resilience researcher, witness of women as educators, promoters, mothers in soup kitchens, Vaso de Leche, PRONOEIs and many social programs organized as community responses, this study explains the Peruvian soup kitchen experience, which has spread to other locations in Latin America.
\end{abstract}

Keywords: female leadership, empowerment, patriarchy, resilience, organized women, leadership in pandemic, soup kitchens

Cualquier uso que se haga de este artículo debe incluir: Autor / Título original de la publicación / ISSN.

* Psicóloga.marthallanos@hotmail.com 
Urgente llamado de la madre tierra, únanse las mujeres y salven al Mundo. Jean Shinoda Bolen

\section{INTRODUCCIÓN}

Desde tiempos inmemorables a nivel mundial, se ejerce una violencia sistemática sobre las mujeres que a nivel mundial representan el $49.5 \%$ de la población. Banco Mundial (2020). Esta situación se repite en el Perú donde las mujeres alcanzarían 16 millones 640 mil y representan el $50,4 \%$ de la población total. (INEI, 2021)

El libro La Guerra más larga de la historia, 4000 años de violencia contra las mujeres, Venegas (2019) es un compendio cronológico de las formas de violencia que se han ejercido sobre las mujeres, las luchas y estrategias para afrontarlas, así como, los avances para mejorar la vida.

Desde el punto de vista histórico, las diferencias entre los sexos y la desigualdad legal están estrechamente ligadas. Nace la diferencia cuando los hombres tomaron el poder y se erigieron en el modelo de lo humano. Desde entonces, la diferencia sexual ha significado desigualdad legal en perjuicio de las mujeres.

El mencionar uno de los libros de Jean Bolen (2008) psicoanalista activista lleva a destacar el rol extraordinario de los millones de mujeres que a nivel mundial hacen posible un desarrollo más humano y solidario y contribuyen al cumplimiento de los derechos humanos. En su obra "Mensaje urgente a las mujeres" reitera el llamado de la madre tierra únanse las mujeres y salven al mundo, presenta una descripción de las cualidades del liderazgo femenino y su propuesta de creación de millones de círculos de mujeres en el mundo

\section{LO FEMENINO}

La esencia de lo femenino: representa la fuerza de la creación de la vida, la fuerza de la semilla de gestación, cuidado y sostenimiento de la vida. Este aspecto es esencial y está presente en todos nuestros pensamientos, ideas, valores que guían nuestras acciones. Es este reconocimiento que nos lleva a amar, nutrir, cuidar y conectar. Este es el principio femenino que representa un cambio de paradigma.

Haciendo recuerdo y tributo a nuestros ancestros la cosmovisión de los pueblos originarios habla del bienestar, de vida es así como los sistemas económicos actuales, de producción y consumo están esencialmente basados en la "destrucción" y no en el "sostenimiento de la vida'.

En los sistemas de valores actuales, predomina: la competencia a nivel mundial sobre los bienes y recursos y de forma individual, un consumismo inconsciente. Se priorizan las estructuras jerárquicas y el ver intereses personales más egocéntricos. Lo descrito refleja los paradigmas masculinos patriarcales.

Un cambio de paradigma funciona desde el principio básico de lo femenino, que es acerca de la creación de la vida y el mantenimiento de la misma. El principio femenino prioriza la conexión, cooperación y solidaridad, se valora la vida por encima de todo. Este planeta es acerca de la vida - la vida que quiere prosperar - no el consumo. Plantea una distribución más equitativa o como naciones juntarnos para hacer frente a los problemas, como la destrucción de nuestro planeta.

Lo femenino se traduce en acciones de compartir, cuidar y mantener la vida. Es acerca de percibir y sentir la conexión de toda la vida y valorarla como algo sagrado teniendo en cuenta no sólo a la humanidad, sino a todas las formas de vida y seres.

O`Donnell (1999) sugiere una pregunta clave: "¿Mi gente es más feliz cuando yo llego o cuando me voy?". El liderazgo desde la perspectiva femenina tiene dos aristas importantes: el contexto y la relación. Cuanto más observo, mejores decisiones voy a tomar. Pasado, presente, futuro... La mirada es más holística e integradora. Asimismo, relación es conversación: diálogo para mejores y significativas interacciones. Con preguntas apreciativas indago en mis valores profundos, para conocerme mejor, centrarme y tener claridad.

El "poder" lo identificamos como el espacio de posibilidades del que disponemos para actuar. Todas 
las personas, sin excepción, tienen dentro de sí la semilla del liderazgo, y está en sus manos, el regarla, cuidarla para hacerla crecer y florecer o bien dejarla secar, morir sin desarrollarse.

Lo femenino hace referencia a lo interno, lo profundo, lo oscuro, lo oculto, el misterio, la noche, la luna, la matriz, la fuerza receptiva que se entrega, se abre, acoge, abraza, espera paciente, gesta, y une, integra, teje redes, intuye, ama. Es el corazón, es la tierra que sostiene y es la belleza e inmensidad del mundo afectivo.

\section{LIDERAZGO FEMENINO}

Líder, es la persona que tiene influencia en un grupo, que los motiva a trabajar para alcanzar metas comunes. Es una persona innovadora, que sabe ir más allá de lo que está determinado y establecido. Es capaz de promover el cambio, juega un papel activo estimulando y dirigiendo una transformación social, educativa y política.

La principal característica se encuentra en el ser, es decir, en la práctica y vivencia de valores. Es el arte de ejercer el poder intrínseco o genuino con consciencia, al servicio del bienestar propio, de un equipo, de la organización y/o de los sistemas a los que se pertenece. Identificando el "poder" como el espacio de posibilidades para actuar.

Según Kirkwood (1986), algunas personas pueden nacer con cualidades y aptitudes de líderes (capacidad para organizar, comunicarse con los demás, tomar la iniciativa, etc.); sin embargo, este potencial puede perderse en el transcurso de la vida si no es percibido a tiempo para desarrollarse y formarse adecuadamente. La principal característica que un líder puede desarrollar se encuentra en el ser, es decir, en la práctica y vivencia de valores.

En el caso de las mujeres, el liderazgo femenino nace del reconocimiento de su identidad como mujer, sus capacidades y habilidades para dirigir un grupo o colectivo. Ellas buscan conciliar, tiene una orientación humanista y empática.

Como hemos visto el estilo de liderazgo femenino es un estilo colaborativo, abierto, democrático, busca consenso, es conciliador, de trabajar en equipo y de compartir responsabilidades y trabajo. La mujer no busca tanto el éxito social que parece proporcionar el poder o liderazgo, su desempeño se basa en búsqueda de equilibrio y armonía vinculadas con la inteligencia emocional, horizontalidad y menos orientaciones jerárquicas.

El empoderamiento femenino es algo más que el acceso de mujeres a la toma de decisiones; es un proceso que necesita de la auto-percepción, el auto-reconocimiento y la auto-valorización de las capacidades, pero también tener confianza en sí misma e iniciativa, capacidad de adaptación y flexibilidad, motivación e intuición, practicar una escucha activa y una buena empatía son los ingredientes básicos de nuestra Inteligencia Emocional.

La líder es la mujer que, consciente y responsablemente, emprende el camino para liberarse de los condicionamientos e influencias de siglos de patriarcado, recuperando, así, la confianza en sí misma y el recuerdo de su esencia. Su visión y acción es de integración de todos los niveles de su ser: corporal, emocional, mental y espiritual.

El liderazgo femenino nace del reconocimiento de su identidad como mujer, sus capacidades y habilidades para dirigir un grupo o colectivo. Entonces el liderazgo femenino es un nuevo paradigma social que permite la emergencia del talento femenino.

Sara Berbel Sánchez (2014) nos presenta un cuadro de las diferencias entre el liderazgo femenino y el liderazgo masculino. 


\section{Tabla 1}

Diferencias entre liderazgo femenino y masculino

\section{Liderazgo masculino /transaccional}

- Estilo competitivo y agresivo.

- Existencia de estructuras jerárquicas.

- Objetivo básico: triunfar.

- Evitación de emociones.

- Concentración de los resultados finales.

- Pensamiento racional.
Liderazgo femenino/transformacional

- Estilo de trabajo cooperativo y en equipo.

- Estructuras poco jerárquicas.

- Objetivo básico: lograr la calidad.

- Emociones y competitividad

- Atención a los procesos.

- Combinación del pensamiento racional con el intuitivo.
Tanto el líder como la líder son artistas, creadores, agentes de transformación, gracias a la integración de lo masculino y femenino.

\section{PATRIARCADO y MACHISMO}

El Sistema Patriarcal es el desencadenante de la violencia de género. En este sistema, la diferencia sexual se presenta como base y fundamento de la discriminación que inspira su ideología. Lo biológico queda erigido en destino fatal, las leyes y los valores del patriarcado, implican una visión muy disminuida de la mujer.

Mencionamos que el patriarcado ha limitado la expresión del liderazgo de la mujer. Coria (1986) "El sexo oculto del Dinero: Formas de la dependencia femenina", indica que: El patriarcado es un modelo de vínculo entre los géneros, que se caracteriza por establecer las diferencias entre ellos en términos jerárquicos. Establece una escala jerárquica, a la que se considera de origen natural, en cuyo escalón superior se instala a los varones de la especie. Es una manera de clasificar a los seres humanos en superiores e inferiores. He podido comprobar que aquellos hombres y mujeres que se animan a revisar el modelo llegan a estar en mejores condiciones para construir un entramado de vínculos con mejor calidad de vida

El patriarcado es un sistema integral que se hace más visible en la conformación de los poderes del estado y el conjunto de la sociedad (normas, costumbres, creencias) Es una forma de sociedad en la que el hombre tiene la supremacía y relega a la mujer, a lo femenino, a un segundo plano. Los hombres, tienen intereses concretos y fundamentales en el control, uso, sumisión y opresión de las mujeres. Esta relación de poder provoca desigualdad entre los dominadores: los hombres, y los subordinados: las mujeres.

Las discusiones sobre patriarcado generan mucha controversia por las implicaciones que este tiene tanto política como filosóficamente. Es también un concepto relativamente difícil de entender. Machismo y patriarcado no son sinónimos.

Los estudios de género y el feminismo hablan del machismo generado por el patriarcado como un fenómeno que tiene dos pilares: uno psicológico, y otro material. En lo psicológico, una manera de pensar en la que la mujer queda minusvalorada y cosificada. En lo material como la fuerza de lo económico y poseedor de bienes y acceso a lo laboral remunerado. De este modo, el aspecto psicológico y el material se retroalimentarían, dando lugar a individuos cuyas actitudes machistas son reforzadas por el medio en el que viven y que ellos contribuyen a reproducir mediante sus acciones.

Gerda Lerner (2019) confirma que el control sexual de las mujeres está relacionado con la dependencia a la protección paternalista que afronta en las diferentes etapas de su vida, la mujer siempre está subordinada y protegida. La Hegemonía masculina en el sistema de símbolos adoptó dos formas:

a.- La privación de educación a las mujeres y

b.- El monopolio masculino de las definiciones. 
Para Marcela Lagarde (2019) académica, antropóloga e investigadora mexicana, etnóloga, representante del feminismo latinoamericano, la dominación patriarcal agudiza y amplía la brecha entre mujeres y hombres, siendo responsable de la feminización de la pobreza, la marginación de las mujeres y el feminicidio. Las ideologías patriarcales no solo explican y construyen las diferencias entre mujeres y hombres como biológicamente inherentes y naturales, sino que mantienen y agudizan otras formas de dominación.

El feminismo, según Lagarde (2019), constituye una afirmación intelectual, teórica y jurídica de concepciones del mundo, modificaciones de hechos, relaciones e instituciones. Indica también que el feminicidio en su acepción general se entiende como el asesinato intencional de una mujer o de una niña. El feminicidio es perpetrado generalmente por los hombres, pero a veces pueden estar involucradas mujeres integrantes de la familia. Sus formas difieren de los homicidios de hombres.

Victoria Sau Sánchez (1981) activista política y feminista española, tiene como obra de mayor influencia su Diccionario ideológico feminista. Ella crea unos fundamentos nuevos que sustentan un análisis más global y más innovador. Sus aportaciones llegaron muy lejos, trató temas como la división sexual del trabajo, la maternidad, el ciclo menstrual, el patriarcado y las guerras.

La violencia de género, tiene sus raíces en la estructura patriarcal. La ideología se imparte mediante el adoctrinamiento socializador desde el nacimiento y a lo largo de la vida. Las personas llegan a la adultez convirtiéndose en defensoras y militantes de la ideología impuesta.

Para combatir esta lacra arraigada en la sociedad se pueden realizar acciones a corto y largo plazo, tales como:

A. Evitar la violencia simbólica, que es aquella que, a través de patrones estereotipados, mensajes, valores, íconos o signos transmite y reproduce dominación, desigualdad y disminución en las relaciones sociales y la subordinación de la mujer en la sociedad. La modalidad más habitual que adquiere es la violencia mediática.

B. La corresponsabilidad, es decir, la necesidad de que mujeres y hombres se responsabilicen de las tareas domésticas del cuidado de hijas/os y personas dependientes.

C. El liderazgo, permitiendo que las mujeres mejoren su posición y se realicen según sus habilidades y talentos innatos.

Existen otras muchas opciones para cambiar el sistema patriarcal, pero la clave radica en cambiar la consciencia, tanto individual como colectiva de las personas, hombres y mujeres, respecto a las creencias que el patriarcado promulga. Los colectivos de mujeres están trabajando su dolor ancestral e intergeneracional por los miles de años de injusto maltrato.

Aunque sean dos conceptos muy relacionados, el machismo y el patriarcado no hacen referencia a lo mismo. El machismo es un conjunto de creencias, sesgos cognitivos y actitudes que predisponen a las personas a actuar como si la mujer tuviese menos valor que el hombre, mientras que el patriarcado es definido como un fenómeno social que históricamente ha sido el motor del machismo y de ciertos privilegios de los que solo disfruta el hombre.

Mientras que el machismo es expresado a través de los individuos (independientemente de si son hombres o mujeres), el patriarcado es algo que existe en los grandes colectivos, una dinámica de poder que solo se entiende si tenemos en cuenta muchas personas a la vez.

El machismo surge del sistema de creencias, actitudes y conductas que recrean el poder, la dominación masculina y la subordinación femenina. Machismo son esas conductas, mensajes y acciones cotidianas que ubican a los varones en una situación de supremacía en relación a las mujeres y otras personas feminizadas por el patriarcado. No es solo un sistema de dominación cultural y se cree que está relacionado con el sistema de propiedad.

El patriarcado es entendido como un fenómeno que va de generación en generación, y es por ello que 
se ha llegado a hipotetizar una relación entre este y la idea de propiedad. Las mujeres han sido concebidas como un recurso, algo que se puede poseer y con lo que los patriarcas de la familia se han dedicado a comerciar, ya sea para tener mano de obra barata (aplicada normalmente a las tareas del hogar) como para poder tener descendencia (algo que también está vinculado al ámbito doméstico y, por lo tanto, privado).

Antiguamente la mujer no podía aspirar a ser propietaria, ya que solo se ocupaba de los bienes necesarios para el bienestar de la familia, desventaja incluso cuando empezó a ser normal la participación femenina en trabajos fuera de casa.

En general los hombres no son capaces de razonar en base a lo que significa ser mujer, solo piensan en el propio beneficio de las situaciones. Además, presentan un repertorio de ideas estructuradas y fundamentalistas, que dificulta el cambio de ideas y acciones.

El machismo es la enfermedad, visible del patriarcado, Isabel Allende (2007) indicaba que las mujeres producen el $70 \%$ de los alimentos y realizan dos tercios del trabajo mundial, ganan una décima parte de lo que perciben los hombres y son propietarias del $1 \%$ de la tierra. Asimismo, las mujeres son las responsables de desarrollar el trabajo del cuidado de las personas, invisible y poco reconocido y menos aún monetizado en nuestra sociedad y se le llama Economía del Cuidado actualmente en debate.

En un estudio reciente en Chile, González (2013) destaca el papel socializador del machismo como eje central. Las mujeres entrevistadas, estaban confusas y con miedo, con una culpabilizarían de las mujeres hacia ellas mismas y las demás, quedando así el machismo como una responsabilidad fundamental de las mujeres.

Aunque los hombres son vistos como los principales ejecutores del machismo, las mujeres se ven como la fuente socializadora de éste, quitando responsabilidad a los hombres en ello, (Casas, Riveros y Vargas, 2012). Las mujeres señalan que esto se manifiesta, ya sea de forma directa o indirecta, donde se presenta un tipo de lenguaje despectivo, discriminatorio, déspota e hiriente que se puede dar de manera verbal o no verbal (movimientos, gestos) (Gomes, 2008), para conseguir herirlas con el fin de menospreciarlas, hacerlas sentir inferior y por tanto manipularlas para obtener lo que ellos desean, haciéndolas sentir que sea cual sea su opinión, e incluso aunque tengan la razón, sus argumentos no son válidos debido al pensamiento absolutista y narciso por parte de los hombres, creyendo que siempre están en lo correcto.

La guerra injustificada y cobarde que inició el hombre contra la mujer ha tenido un impacto en la vida de millones de mujeres a lo largo de la historia. Millones de mujeres interiorizaron una falsa inferioridad impuesta por el hombre a fuerza de golpes, religión y socialización. Los efectos de tamaña opresión no desaparecen sin mencionar que los hombres, en buena parte del orbe, siguen activamente coartando la libertad de las mujeres, haciendo leyes o negándose a derogar.

\section{LIDERAZGO FEMENINO EN TIEMPOS DE CRISIS}

Liderar es tomar decisiones, pero que en épocas de crisis se requiere de serenidad, carácter y astucia. Serenidad para no permitir que las tensiones de la situación nublen el juicio; carácter para asumir la responsabilidad propia sin titubeos; y astucia para persuadir con tacto a terceros respecto de la pertinencia de las estrategias por implementar.

Los liderazgos femeninos dejan huella. En tiempos de crisis, más que nunca las organizaciones necesitan líderes que se centren en las personas, que sean empáticos, que sean agentes de cambio, que desarrollen una motivación inspiradora, que confíen en sus seguidores, que promuevan la colaboración, la comunicación y el trabajo en equipo. Estas habilidades han adquirido mayor importancia con la pandemia del Covid-19 que ha puesto de manifiesto su valor; y aprecio para las mujeres poseedoras de dichas cualidades.

El mundo necesita de más mujeres en puestos de decisión para avanzar hacia propuestas de solución para amenazas graves como el calentamiento global, la inestabilidad política y la a desigualdad económica que persiste. 
Para Randi Davis (2021) representante del PNUD Trinidad y Tobago, Curacao, Aruba y St Marteen, la COVID-19 es una amenaza para revertir el trabajo para la igualdad de género y el liderazgo de las mujeres. Las mujeres que realizaban una gran parte del trabajo de cuidado no remunerado en el hogar, estimado en tres veces más que los hombres, tienen ahora que administrar, ver la higiene del hogar, educar a sus hijos $\mathrm{y}$, al mismo tiempo, mantener sus medios de vida.

A nivel global, cada vez más mujeres sufren violencia en sus hogares, en las calles y en el lugar de trabajo. La pandemia solo ha intensificado este otro "virus" de la violencia contra las mujeres, en todas las regiones y contextos culturales.

En América Latina y el Caribe, donde el 39\% de los hogares están encabezados por una mujer, hogares monoparentales, las políticas que permiten a las mujeres reincorporarse a la fuerza laboral de manera segura y con sus esfuerzos, evitan que las familias vuelvan a caer en la pobreza (SELA, 2021). Sin embargo, se incrementa las responsabilidades de las mujeres por los temas de la educación no presencial y otros.

En esta crisis sanitaria cuando una persona acude a un centro de salud, lo más probable es quien la reciba sea una mujer como parte de la primera línea de atención y que, al volver a casa, sea también una mujer quien se ocupe de los cuidados hasta la recuperación de su salud. Los datos avalan esta experiencia: las mujeres son el $73 \%$ del personal de enfermería de la región, y las principales responsables del cuidado en los hogares. Asimismo, pandemia posiblemente dejará en la región a 118 millones mujeres y niñas en la pobreza (ONU MUJERES, 2020).

Un análisis publicado por CEPAL nos indica sin embargo que siguen estando subrepresentadas en los comités de toma de decisión en el manejo de la crisis y solo un $25 \%$ tiene roles en cargos directivos y con una brecha salarial del 25\% (Vaca T., 2019). Esto implica cortedad de visión e incide negativamente en la capacidad de respuesta eficiente, desaprovechando el liderazgo, el conocimiento, la visión y la experiencia de las mujeres.
Un artículo reciente de Randy,D. (2021) menciona que Harvard Business Review mostró que las muertes confirmadas por la COVID-19 en el primer semestre de 2020 fueron seis veces más bajas en los países liderados por mujeres. Lo cual es un indicador de este liderazgo femenino a niveles de política y solución de crisis. Casos como Alemania, Nueva Zelanda, Taiwán y otros son ejemplos reales del liderazgo político femenino y su impacto en los problemas como en este caso el COVID-19.

El impacto de la pandemia en las mujeres fue hacer visible el Liderazgo femenino. Tenemos muchos ejemplos de mujeres que han demostrado una enorme capacidad de recuperación y habilidad en la gestión de hogares mientras se encuentran en la primera línea de la pandemia. Las mujeres que lideraron equipos tuvieron que detectar cómo mantener al equipo cohesionado en un escenario de tanta incertidumbre y sin certezas para darle al grupo.

En este punto los testimonios indican que fue crucial la sinceridad y mostrarse como los humanos que somos. Compartir debilidades o inseguridades por no poder dar una garantía de cómo iba a seguir el año. Además, fue beneficioso permitir expresar las sensaciones y sentimientos porque el equipo comparte más que un proyecto: comparte angustias, temores, consejos, lo que pasa con los hijos o con la falta de socialización. El vínculo trascendió el ámbito laboral y se profundizó el liderazgo horizontal, todo ello debido a la pandemia.

Uno de los rasgos fundamentales del liderazgo en pandemia fue la escucha para poder entender cómo están, qué necesidades habían, quienes estaban en mejores condiciones de asumir más responsabilidades o quienes necesitan ser ayudados; también quiénes podían trabajar mejor. Todo ello mantuvo la cohesión y la unidad del equipo. Otra característica de liderazgo que resultó beneficiosa fue mostrarle a cada persona del equipo cuán empoderado/a estaba para poder capitalizar el recorrido.

La red de trabajo es muy importante porque actúa también como contención. Todos los miembros -inclusive el líder- saben que pueden contar con ellos. Un líder también debe dejarse ayudar y potenciar 
y promover la capacidad del equipo para plantear soluciones.

En las redes radica el corazón del liderazgo y la posibilidad de que las mujeres tengan creencias que limitan su autopercepción y estima que muchas veces se autoimponen por miedo o inseguridad. Una red fuerte hace que no se descuiden otros roles. No es lo mismo solas que con red.

El Secretario General de las Naciones Unidas, Antonio Gutiérres, señala que la igualdad de género es una cuestión de poder; poder que los hombres han guardado celosamente durante siglos. Debemos, transformar y redistribuir el poder con urgencia, si queremos salvaguardar nuestro futuro y nuestro planeta. La constatación de la eficaz gestión de las mujeres durante esta pandemia permitirá consolidar los cambios para que más mujeres estén representadas en los espacios de decisión, a la vez que permita reflexionar sobre las políticas tradicionales y promueva un ejercicio de poder político inclusivo, que, basado en un enfoque de derechos, promueva el respeto, la igualdad, la diversidad y el respaldo a los liderazgos femeninos.

Laura Tabares, directora ejecutiva de Intuic reconocida como (la primera plataforma digital accionada por mujeres y enfocada en promover el liderazgo femenino) en una entrevista para Forbes México por Mónica Garduño en mayo 2021, comentó que "La pandemia democratizó el juego y lo emparejó, nos dio la oportunidad de que pudiéramos hacernos cargo de responsabilidades laborales y familiares. Ayudo a las mujeres a ver una realidad diferente.

Para Tabares (2021) la pandemia hace que las empresas vean y descubran las habilidades que han mostrado las mujeres en sus vidas con sus habilidades como la empatía, conciencia y visión humanista

La pandemia abrió una gran puerta para que las empresas tuvieran más cuidado en los programas de apoyo para las mujeres que trabajan y estos programas que ya existían sobre cómo apoyar mujeres para desarrollar más habilidades empezaron a enriquecerlos con otro tipo de actividades. (Garduño entrevista a Tabares, 2021)
Los logros conseguidos demuestran la capacidad de la mujer para hacer frente a los obstáculos. $\mathrm{Su}$ adaptación a diferentes aspectos, su forma de organización, sus valores, y demás habilidades que la mujer tiene, ya son reconocidos por muchos, poniéndolas en cargos realmente importantes.

Diferentes estudios demuestran que el liderazgo femenino es un medio de transformación personal y colectivo. La mujer aplica sus habilidades por las relaciones interpersonales y motivacionales para transformar el interés individualista por un interés colectivo guiado hacia la empresa como totalidad.

Las empresas, necesitan de lo que la mujer puede aportarles liderando, es mucho y no deja margen a su omisión. El manejo de conflictos, la complementariedad, los cuidados, las formas, las claras visiones de horizontalidad y más cualidades, son aspectos que se fortalecen en el liderazgo de mujeres. Y todo ello, se debe a cómo fue y es la esencia e historia de la mujer. También en su condición de madre desarrolla muchas virtudes que las vuelca, en diversos planos.

Nuevos paradigmas empresariales son los que deben arribar, modificando lo social, cultural y económico. Una feminización empresarial, con muchas mujeres en cargos claves. Las empresas deben entender las conciliaciones de la mujer en el trabajo con todos los otros aspectos de la vida. De lo contrario, el precio que paga una mujer ejecutiva, líder, es muy alto.

La cualidad más importante que debe tener un buen líder empresarial, es la inteligencia emocional. Y las mujeres, por el hecho de ser madres, pueden usar mejor esta "inteligencia emocional" para descifrar códigos emocionales de otras personas. El nuevo liderazgo empresarial pasa por enaltecer cualidades que la mujer posee y debe potenciar: escucha, empatía, capacidad de trabajo, humanismo, optimismo y superación.

La autoestima es una necesidad humana vital, que fortalece lo profesional y social del individuo, favoreciendo la propia identidad, la autoestima elevada puede contribuir al éxito. La mujer puede ser más 
sensible que el hombre, en relación a su autoestima. Cuando se siente muy criticada, concluye que no la quieren, porque no es digna de ser querida.

La cultura exige que la mujer sea madre, esposa, hija, ama de casa. Si la mujer trabaja fuera de la casa su situación se complica, porque tiene que cumplir con el trabajo, sin descuidar sus otras obligaciones. La mujer que trabaja puede sentirse sola en una situación, en donde tiene que demostrar constantemente su valor, tanto a las personas de su mismo sexo, como a las del sexo contrario. Cuando la mujer es tratada como inferior, puede fácilmente acabar creyéndolo.

\section{El empoderamiento}

El empoderamiento significa aumentar la autoridad de las personas sobre los recursos y las decisiones que afectan su vida. En este proceso las mujeres incrementan su capacidad de diseñar sus propias vidas, y su entorno, una evolución en la concientización de las mujeres sobre sí mismas, en su estatus y en su eficacia en las interacciones sociales.

El empoderamiento, por lo tanto, se entiende como un proceso de superación de la desigualdad de género. Se busca que las mujeres reconozcan que hay una ideología que legitima la dominación masculina y que entiendan que esta ideología perpetúa la discriminación. La subordinación ha sido vista por la ideología patriarcal como natural.

Es importante crear conciencia de la discriminación de género, significa que las mujeres modifiquen la imagen de sí mismas y las creencias sobre sus derechos y capacidades y desafíen los sentimientos de "inferioridad".

Para Empoderar a las Mujeres Rurales, Ospina (1998) propone un camino metodológico alterno a través del cual empezar a superar los trabajos centrados en diagnósticos cuantitativos y sectoriales. Hace un planteamiento más holístico y contundente sobre los grandes obstáculos que impiden la equidad de género en el desarrollo rural y que están referidos a la situación estructural de las mujeres en las sociedades rurales, en comparación con la situación de los hombres como miembros integrantes de las mismas.
La pandemia ha demostrado que los pueblos y comunidades conservan un gran acervo cultural y social que, entre otras cosas, les ha permitido enfrentar con éxito varios de los desafíos provocados por el virus.

Ospina (1998) plantea la participación de las mujeres en el escenario comunitario como fuente de empoderamiento, propone el afianzamiento del Trabajo comunitario a través de grupos vecinales, la participación femenina en instancias de concertación y planeación del desarrollo sectorial y municipal, así como el trabajo de las mujeres en los proyectos de desarrollo comunitarios.

Es necesaria una mayor organización y participación política de las mujeres y se sugiere mayores y mejores procesos de formación para fortalecer la autoestima, afianzar la seguridad y proporcionarle más campos de emprendimiento y conocimiento tanto técnico como administrativo. Todo ello brindará mayor impacto a la participación femenina.

\section{EDUCACIÓN y GÉNERO}

Según Nussbaum (2011), nos encontramos frente a una "crisis mundial en materia de educación", y uno de los síntomas es el debilitamiento de las artes y las humanidades. Para la autora, esta crisis pasa desapercibida y sus consecuencias serán muy perjudiciales, ya que, "con el afán de la rentabilidad en el mercado global, están en peligro los valores para el futuro de la democracia".

López Calva (2016) hace un extenso análisis de las ideas de Nussbaum y de Morín y diseña un instrumento para investigar la visión de estudiantes y profesores universitarios acerca del ser y el deber ser de la educación superior en una universidad privada del Estado de Puebla. Martha Nussbaum plantea el dilema entre la que llama educación para la renta y que considera predominante en el contexto mundial actual dominado por la economía y la educación para la democracia, que promueve la formación integral de seres humanos y ciudadanos. Se encontró diferentes posiciones entre los profesores y alumnos. Parte de una idea de eficiencia íntimamente ligada a la pertinencia 
y la equidad para contribuir a la construcción de sociedades viables en el mediano y largo plazo.

En cuanto a educación no formal, Corvalán (1990) distingue acertadamente entre experiencias y trabajos que se enmarcan dentro de la educación popular, por una parte, y la capacitación feminista por otra. La primera «se orienta con más énfasis a la promoción de la mujer de los sectores populares», mientras que la segunda «representa la búsqueda de una propuesta alternativa de educación para las mujeres». En otras palabras, la primera se ha focalizado mucho más en las cuestiones de clase que en las de género.

Si bien una característica particular de América Latina es la proliferación de organismos, programas y experiencias de educación no formal para mujeres, una de sus falencias más evidentes ha sido la falta de sistematización, evaluación y difusión; por ello, son muy pocos los trabajos en esta área.

El trabajo de Corvalán agrega otras importantes líneas para futuro.

a) El papel de la educación en la capacitación de la mujer para la toma de decisiones, y la participación igualitaria en los espacios de poder.

b) Procesos, mecanismos, metodologías aptas para producir cambios en la conciencia femenina y en las relaciones de género en los ámbitos públicos y privados.

c) En un sentido similar, hace falta mayor información sobre los contenidos y perspectivas adecuados para capacitar a la mujer en un mayor y mejor conocimiento de su sexualidad, de sus derechos como ciudadana y de sus posibilidades en el mercado de trabajo.

Por último, es sabido que en nuestra Región pocas veces se transfieren los resultados de las investigaciones a la formulación de políticas o de programas de capacitación. En este sentido, por más que se incrementen los esfuerzos para cubrir los distintos temas sugeridos e inclusive otros, está claro que la investigación en este tema no alcanzará su máximo aprovechamiento a menos que se creen y se potencien los mecanismos institucionales que permitan una efectiva articulación entre investigadores, planificadores y ejecutores de políticas de Igualdad de Oportunidades para la Mujer en los ámbitos de la educación.

Es relevante indicar que, en la educación no formal, el contexto familiar, comunitario, local y regional son tomados en cuenta como factores de enseñanza y aprecian el valor de las no profesionales o promotoras comunitarias (prioritariamente son mujeres) mujeres que actúan como un puente entre los educadores profesionales, sistemas formales y la comunidad. Esta inclusión de Promotoras Comunitarias ha generado en el caso de Perú (Llanos, 2009) un espacio de oportunidad para el descubrimiento de la capacidad de gestión de las mujeres, de sus estilos armónicos de liderazgo y de su gran resiliencia haciendo viable y con múltiples ventajas su inserción como Promotoras de la Comunidad y su participación en cualquier acción educativa.

Las Promotoras Comunales y o Animadoras constituyen un valioso grupo humano que en forma bastante silenciosa son fundamentales en el desarrollo comunitario. La gran mayoría son mujeres seleccionadas en la misma comunidad; generalmente pertenecen a la misma clase social y cultural que los niños/niñas/adultos beneficiarios de los proyectos y son escogidas en base a su compromiso con la tarea de desarrollo educativo, en campos de la salud, agricultura, planeamiento y otros.

Ellas contribuyen al crecimiento de las potencialidades locales y a la creación de un genuino sistema de reciprocidad, en el que se benefician tanto las familias, los promotores, como la comunidad en su totalidad. A través de esta estrategia los programas han tenido una inserción más adecuada en sus localidades de trabajo; han respetado los liderazgos existentes y han propiciado nuevos canales de participación fortaleciendo los recursos humanos locales y el empoderamiento de las mujeres como gestoras de desarrollo (Llanos, 2016).

El estudio "Las mujeres en la economía social y solidaria" (ESS) realizado en España por la Red de Economía Alternativa y Solidaria (REAS) en un grupo 
de mujeres emprendedoras y empresarias de la ESS, se estableció un "Perfil de competencias y necesidades de formación para incrementar y visibilizar este liderazgo", entre las principales competencias identificadas en estas mujeres y en las que tendrán que desarrollarse en futuras líderes se encontraron márgenes de aprendizaje, que requieren visibilidad, promoción para lograr un estilo de liderazgo propio. En este diseño del perfil se comparte que el contexto puede aportar cierta variedad y es un reto que el estudio ha intentado abordar combinando diferentes puntos de vista.

Mencionaremos los resultados más relevantes de este perfil que aporta mucho en la comprensión del liderazgo femenino y sus posibilidades para una mayor difusión.

Las competencias "blandas": las mujeres de la ESS expresaron ser competentes en términos de habilidades y actitudes de empatía, comprensión, conocidas como "blandas", (mal llamadas diría cualidades vinculadas a lo femenino) aun así las mujeres muestran evidente afán por trabajarlas y reforzarlas. El estudio confirma que fortalecer las competencias interpersonales, emocionales y cognitivas de las personas se considera importante para potenciar y transformar el ecosistema laboral de la ESS.

Las competencias "duras": sigue siendo relevante para el desarrollo de la ESS. Se considera como duras a aquellas habilidades y destrezas que se adquieren a través del conocimiento y la experiencia profesional, técnica y las acciones formativas dirigidas a fortalecerlas tienen que ajustarse a las características del contexto.

El entorno y su clima laboral: En las ESS se tienen las condiciones laborales significativamente más igualitarias y un clima laboral mucho más considerado y respetuoso que lo observado en otros entornos de economía convencional. El hecho de ser economías solidarias promueve la autorreflexión y autocrítica, es decir, la permanente mejora.

Diversidad: La incorporación de la diversidad socioeconómica y cultural en sus estructuras es uno de los retos del entorno laboral de la ESS más prioritarios.
Equidad: Es necesario fomentar la coexistencia armónica de diferentes estilos de liderazgo, visibilizando las cualidades del liderazgo femenino, fortaleciendo las competencias a través de la formación.

Estilo de liderazgo femenino: Las mujeres tienen su propio estilo de liderazgo: cooperan, cuidan, democratizan y humanizan los procesos. cierran los círculos atendiendo los aspectos empresariales cuya importancia reconocen. El liderazgo femenino es humanista y muchas veces invisible, lo que debería inspirar la comprensión y expansión de este liderazgo.

Retos para una formación transversal: Además de fortalecer las competencias de las mujeres, para una mayor igualdad de género, también los hombres deben formarse y adquirir las competencias propias del estilo de liderazgo femenino, deben fortalecer las actitudes que apoyen para lograr una mayor visibilidad de la labor de las mujeres; fomentar de forma proactiva y deliberada su participación.

\section{CASO PERUANO: PANDEMIA Y LIDERAZGO FEMENINO}

\section{Realidad Peruana}

En el Perú, el Estado, a través del "Programa Innóvate Perú" del Ministerio de la Producción está comprometido con el impulso y cofinanciamiento de proyectos que buscan empoderar a la mujer en el liderazgo de empresas innovadoras y emprendimientos en el país.

Con relación a los sectores y actividades con mayor presencia femenina en el 2018 destacaron restaurantes $(61,1 \%)$, comercio $(58,5 \%)$, alojamiento $(50,7 \%)$, otros servicios $(47,8 \%)$, telecomunicaciones con el $42,7 \%$ y los servicios profesionales $(41,6 \%)$. Con menor presencia femenina fueron: manufactura $(38,6 \%)$, electricidad, gas y agua $(35,7 \%)$ y sector agropecuario $(32,3 \%)$.

Para la presidenta de la Comisión de Desarrollo de la Mujer Empresaria de la Cámara de Comercio de Lima, Marina Bustamante, si bien estas cifras denotan el avance de las mujeres en los negocios, todavía en el Perú hay diferencias económicas, sociales, financieras 
y educativas que son desfavorables para el género femenino.

Algunos proyectos exitosos con participación femenina que han sido cofinanciados por Innóvate Perú. Ayni, empresa liderada por Adriana Caycho, que cuenta con una marca de moda sostenible que promueve el comercio, a través de la colaboración directa y el empoderamiento de diversas comunidades de artesanos de Cusco y Puno. En sus colecciones se rescata la riqueza y la alta calidad de la alpaca y el algodón Pima y se revaloriza nuestras técnicas ancestrales. Ayni es beneficiaria del Concurso de innovaciones tecnológicas de alto impacto.

En el caso de los emprendimientos innovadores, destaca Cristal Mixcan y su empresa Gervitro, que usa la biotecnología vegetal para propagar de forma masiva especies ornamentales en peligro de extinción. Las plantas de Gervitro se cuidan solas los primeros 6 meses de vida en un formato innovador. Este proyecto resultó elegido en la quinta generación del Concurso StartUp Perú.

Existen múltiples alternativas para incrementar el liderazgo femenino en instituciones, pero la pandemia ha agravado esta situación especialmente con las mujeres, quienes han asumido muchos roles en la educación de los niños en casa y el cierre de instituciones limitando así sus ingresos y participación. ¿Cómo afrontar estos desafíos?

Inicialmente se sugirió la construcción de una red de conexiones profesionales, directorios, seminarios, para que las mujeres ejecutivas que aspiran a ocupar cargos de la alta gerencia tengan la oportunidad de compartir y adquirir nuevos conocimientos y experiencias con empresarios exitosos.

Para la búsqueda de financiamiento de proyectos, en el caso del Perú existen colectivos liderados por mujeres exitosas, como el Movimiento Manuela Ramos y la Red de Mujeres Empresarias del Perú (RME), que brindan ayuda a negocios liderados por mujeres. Se focalizan en otorgar apoyo económico, educativo y de gestión, dándoles la posibilidad de participar en talleres formativos para adquirir las habilidades administrativas para la rentabilidad de sus negocios.
Asimismo, reciben información sobre sus derechos laborales especialmente vinculado con licencias y derechos por maternidad. Todo ello es básico para reinsertarse al trabajo y estar actualizada con los avances que se han venido desarrollando durante su ausencia.

En conclusión, para convertirse en una líder de éxito es necesario poseer rasgos, características y habilidades que cualquier profesional capacitado y preparado puede desarrollar, independientemente del género. Aunque existen desafíos, con esfuerzo y perseverancia es posible superarlos.

\section{EI hambre acecha. Las mujeres líderes y solidarias fortalecen las ollas comunes en Latinoamérica}

En la situación de Pandemia y retomando la siempre conocida capacidad de cooperación entre las poblaciones vulnerables y de mayor riesgo destacamos la organización de las Ollas comunes. El Perú ha hecho historia con los Comedores Populares que con la Pandemia la crisis se agudizo y no se pudieron dar abasto con la cantidad de ancianos y niños y la situación de cuarentena y ausencia de vacunas.

La pandemia del coronavirus va dejando estragos por donde pasa. En América Latina, esta crisis lleva a mostrar miles de banderas blancas, símbolo de muerte, hambre y pobreza. Es en este escenario que renace la ancestral solidaridad, la cosmovisión de la madre tierra, el bien común y la sabiduría del buen vivir demostrado en el liderazgo femenino.

Los testimonios de muchísimas mujeres que han asumido este liderazgo de proveer alimento a sus vecinos y de promover la organización colectiva en la búsqueda de donaciones de mercados y otros nos han dado ejemplos ciudadanos ya que muchos grupos no han contado con el apoyo de sus municipalidades y sus viviendas en lugares de difícil acceso ha hecho que no fueran beneficiadas con los bonos familiares.

Las ollas comunes en el contexto de la pandemia se han activado, especialmente en lugares donde no existen comedores populares, los lugares son alejados, se facilitan instrumentos básicos de cocina, alimentos y la organización de turnos y tareas. 
Históricamente las ollas comunes han sido de gran ayuda en los terremotos y las inundaciones o catástrofes que periódicamente asolan a las distintas regiones del Perú. Estos problemas ambientales y sociales afectan de manera más trágica a los sectores vulnerables y las ollas comunes son la primera forma que tienen las mujeres a la mano para alimentar a sus familias de manera inmediata.

A diferencia de las ollas comunes, que son organizaciones espontaneas y de corta duración, los comedores populares fueron promovidos por distintas instituciones gubernamentales y ONGs. Ellos cuentan con el liderazgo de comités vecinales y muchas mujeres incansables que han enfrentado crisis sociales, ambientales y políticas durante muchos años.

Sin embargo, debemos ser realistas frente a un tema generacional en el voluntariado. Las mujeres jóvenes, a diferencia de las mayores que protagonizaron este movimiento social de comedores, quieren tener oportunidades para trabajar y ganar dinero antes que cocinar en un comedor o para una olla común. La realidad es otra. El Ministerio de Desarrollo e Inclusión Social (MIDIS) debe coordinar entre las instituciones de apoyo, con los gobiernos locales y las organizaciones vecinales para garantizar la provisión alimentaria. Es muy importante reconocer la solidaridad y liderazgo de las mujeres en este trabajo voluntario.

El Programa Mundial de Alimentos de las Naciones Unidas, revela que las consecuencias socioeconómicas de la pandemia en América Latina y el Caribe han afectado a varios países de la región, con más de 14 millones de personas que sufren por "inseguridad alimentaria severa", es decir, pasan hambre. (PMA, 2020).

\section{La experiencia de las ollas Comunes en Chimbote}

Esta experiencia ha sido descrita por Edwin Azaña (2021) Premio de Periodismo 2020. Muy sabiamente se les llama Mujeres Coraje (Bertold Brecht obra de teatro referencial) que ayudan a combatir el hambre con ollas populares. El escenario de estos testimonios es el cerro San Pedro, lugar alejado del centro de Chimbote en la región Áncash. En esa zona, tres mujeres
Katia, Carmen y Patricia, de distintos asentamientos humanos, organizan a sus vecinas para preparar ollas populares. A veces a leña o con balones de gas, sus ollas y cocinas han alimentado a sus familias y también a niños, ancianos y adultos de los barrios más pobres del puerto de Chimbote en la provincia de El Santa.

Es así que las mujeres del puerto de Chimbote levantaron 45 comedores populares en las zonas más pobres, pero la mitad tuvo que cerrar. Unos por falta de apoyo y otros por contagios de COVID-19. Las ollas solidarias que persisten reparten en promedio 50 almuerzos diarios. Ellas son llamadas madres coraje.

Se necesita desarrollar modelos de autogestión, autoformación y auto-organización se requiere de educación cívica, fortalecimiento de la conciencia cívica, institucionalidad, empoderar a través de la participación ciudadana y las políticas públicas, que deben responder a los derechos humanos y que corresponde al estado dar respuestas sólidas.

\section{Entrevista con Daysi Girón de la Olla común mujeres triunfadoras del sector 1 Collique}

Desde abril del año pasado al iniciarse la Pandemia, Daysi se reunió con 3 amigas y vecinas del sector 1 de Collique y decidieron establecer una olla común para aliviar el tema de muchas mujeres y de ellas de haber perdido el trabajo. La olla Popular de las mujeres triunfadoras como se han denominado, empezó sirviendo 15 a 20 almuerzos diariamente y ahora lo hace entre 70 a 80 raciones diarias. Son 4 amigas y vecinas. Daysi con 4 hijos, Vanessa con 5, Anabel con 1 y Elba con 2, se organizan en turnos para cocina, limpiar, hacer las compras, traer leña y agua que se compra, llevar las cuentas. La comida estrella que más gusta a las familias son las lentejitas con tortilla de verduras (muy nutritivo).

Daysi, Coordinadora de la Olla Común, se considera una líder e identifica que "las mujeres líderes son las mujeres triunfadoras. Declara que ella y su grupo han salido triunfantes frente a las adversidades".

\section{Características de mujeres líderes según participantes de la Olla Común}

- Una líder anima a los demás a no rendirse 
- Busca el bienestar para todos

- Aunque no se tenga ayuda no se bajonea

\section{¿Hay diferencias entre el líder hombre o mujer?}

$\mathrm{Si}$, responde Daysi: Las mujeres como líderes somos más preocupadas por los otros. Los hombres son más machistas, es más lo personal.

Las mujeres tenemos más agallas como decimos, muchas somos madres solteras, muy fuertes.

A la mayoría en mi sector 1 de Collique les ha dado COVID a nosotras también recién en este año, pero fue suave y nos cuidamos en casa.

\section{¿Qué les diría a las mujeres?}

Que nunca agachen la cabeza

Que nunca hay que rendirse

Siempre seguir para adelante

Nos conocimos con mis socias hace 8 años $y$ ahora somos más unidas, queremos cursos de corte de cabello, costura, administración para pensar en un trabajo juntas para el futuro.

\section{MIRANDO AL FUTURO. Mujeres organizadas}

Ha sido una constante en el tiempo que en gran parte de los casos las mujeres hayan liderado ollas comunes en respuesta a situaciones de apremio y hambre, sin embargo algunas voces desde el feminismo han alertado y se han mostrado críticas respecto del rol doméstico que la sociedad ha asignado a las mujeres, quienes han sido responsables de la reproducción, crianza, cuidados de niños y mayores y sostén emocional, mirada que no ha estado exenta en lo que va de esta pandemia, saliendo a la luz pública la precariedad en que muchas mujeres deben sortear el día a día en diversos aspectos de su vida, pero más allá de ello siguen siendo mujeres las que se hacen presentes en estas organizaciones.

Lo anteriormente expuesto son lecciones abiertas del funcionamiento de las ollas. se observa roles de género que se perpetúan, las mujeres cocinan, los hombres traen la comida, supervisan y hay muchos hombres que indican que, si las mujeres no son escuchadas, no hay comida, de modo que colaboran en los procesos de participación armónicos con responsabilidades compartidas. Sin embargo, esto son solo pinceladas iniciales ya que el patriarcado y machismo predomina, aun cuando el feminismo ha logrado instalar sus ideas en el debate público, y los grupos de las ollas se declaran feministas.

A nivel mundial encontramos muchas iniciativas para reducir las brechas de género, sin embargo, las mujeres aún enfrentan obstáculos para alcanzar puestos de liderazgo en las organizaciones. Según el estudio Mujeres en las Juntas Directivas realizado por Deloitte, (2019) solo el $16.9 \%$ de los cargos en las Juntas Directivas a nivel global es ocupado por mujeres.

Se señala que el aumento del número de mujeres en posiciones de liderazgo está totalmente vinculado con el retorno financiero de los negocios. Un estudio realizado por First Round, de Silicón Valley (2015) muestra que las inversiones que cuentan con al menos una mujer en el equipo fundador, tuvieron un rendimiento un $63 \%$ superior a las lideradas solo por hombres.

A nivel global, las mujeres deben enfrentar y superar una serie de desafíos. Entre ellos podemos encontrar a los siguientes:

\section{Falta de financiamiento}

Las mujeres tienen menos probabilidades de obtener financiamiento para desarrollar proyectos y demostrar su capacidad de liderazgo. De acuerdo a un artículo publicado por Forbes, las directoras ejecutivas tienen acceso a menos del $3 \%$ de los fondos de capital de riesgo.

\section{Limitados contactos y conexiones profesionales}

Esto es crucial para conseguir mejores oportunidades laborales y propuestas de inversión, es así como se crean asociaciones que ayudan a desarrollar y expandir un negocio. el $50 \%$ de las mujeres que se dedica a los negocios, señala que "les resulta difícil construir una red de apoyo saludable en campos dominados por hombres".

\section{Maternidad y vida laboral}

Las mujeres líderes enfrentan un gran reto al 
reincorporarse al mundo empresarial luego de haber tomado licencia por maternidad. Es así que la armonía entre la vida laboral y familiar es un desafío auténtico.

\section{Percepción limitada de sus capacidades}

Las mujeres han logrado avances importantes en sus carreras ejecutivas, pero son limitadas en sus funciones dentro de las organizaciones.

\section{Es indispensable y urgente}

Apostar por la educación de calidad para niñas, niños y jóvenes; debemos erradicar todo tipo de violencia de género, pues esta pone a las mujeres en situación de vulnerabilidad y frena su pleno desarrollo profesional y social; en el mismo orden de ideas, promover la creación de redes de apoyo entre mujeres servirá para establecer un nuevo paradigma de mayor igualdad.

Abrir espacios. Las lideresas del futuro precisan hoy de espacios propicios para cultivar sus talentos y capacidades. Construir un mundo de oportunidades iguales para todos y todas es el gran desafío de nuestra generación.

Invertir en la igualdad de género es necesario para una recuperación plena y sostenible de la pandemia. La educación debería estar en el centro de la lucha contra la desigualdad. El análisis de la educación nos revela una extrema desigualdad educativa y problemas serios de inclusión social. Luego de casi un año y medio afrontando el COVID-19 las desigualdades y limitaciones del sistema de educación y salud son más evidentes. El acceso a la educación y de calidad ha sufrido un retroceso notable, siendo las poblaciones pobres, rurales e indígenas las más afectadas.

Necesidad de cambios profundos, expansión y diseminación de los significativos liderazgos femeninos para un mayor reconocimiento de las posibilidades y potenciales de las mujeres.

\section{REFERENCIAS}

Allende, I. (3 de marzo, 2007) Cuentos de pasión. TED

Azaña, E. (5 de julio 2020). Mujeres coraje combaten el hambre con ollas populares- Historias De Cuarentena, Actualidad, Últimas Noticias. https:// wayka.pe/mujeres-coraje-combaten-el-hambrecon-ollas-populares

Berbel Sánchez, S. (2014).Liderazgo y género: análisis de las divergencias conceptuales y sus efectos en la teoría y práctica feminista. Cuadernos de psicología, 16 (1).

Banco Mundial (2020) Población mujeres (\% del total) 1960-2020. https://datos.bancomundial.org/ indicator/SP.POP.TOTL.FE.ZS

Bolen, J. (2008). Urgent Message from Mother: Gather the Women, save the World. First Time in Paperback

Cámara de Comercio Lima. (2021) Hacia el empoderamiento de la mujer empresaria. https:// lacamara.pe/tag/comision-de-desarrollo-de-lamujer-empresaria

Casas, L., Riveros, F. y Vargas, M. (2012). Violencia de Género y la Administración de Justicia. Universidad Diego Portales. Chile.

Chamorro, T. (2020). Will the Pandemic Reshape Notions of Female Leadership? Harvard Business Review

CEPAL (2021). La autonomía económica de las mujeres en la recuperación sostenible y con igualdad

Chong, C. (2015). Startups founded by women are doing way better than ones founded by men, says top firm First Round Capital. Business Insider, July 30, 2015.

Coria, C. (1986) El sexo oculto del Dinero. Formas de la dependencia femenina. Red Ediciones.

Corvalán, G. (1990.) Mujer y Educación en América Latina y el Caribe. Cuadernos de Discusión, Centro Paraguayo de Estudios Sociológicos.

Deloitte (2019). Mujeres en las Juntas Directivas Una perspectiva Global. Sexta edición Economía Solidaria. Feminismos 
Garduño, M. (2021). La pandemia hizo visible lo invisible en posiciones de liderazgo femenino: Laura Tabares https://www.forbes.com.mx/ mujeres-pandemia-visible-invisible-posicionesliderazgo-femenino-laura-tabares/

González Vásquez (2013). Machismo ¿Una forma de vivir? Universidad del Biobío Facultad de Educación y Humanidades Departamento de Ciencias Sociales Psicología. CHILE

Gomes, P. (2008). Violencia y género en la sociedad patriarcal. Las estructuras elementales de la violencia: ensayos sobre género entre la antropología, el psicoanálisis y los derechos humanos. $\quad$ http://www.ava.unam.edu.ar/ images/12/pdf/ava1210gomespereira.pdf

INEI (2021) En el Perú más de 16 millones 600 mujeres celebran su día este 8 de marzo. https:// www.inei.gob.pe/prensa/noticias/en-el-peru-masde-16-millones-600-mil-mujeres-celebran-sudia-este-8-de-marzo-12774/

Kirkwood, J. (1986) Ser política en Chile las feministas y los partidos Facultad Latinoamericana de Ciencias Sociales. Flacso

Lagarde, M. (2019). El feminismo es colectivo, ninguna causa la ha ganado una mujer sola. http://www.mujeresenred net

Lerner, G. (2019). El origen del sistema patriarcal y la construcción de las relaciones de género. Crítica.

López Calva, M. (2016). Educación y formación para la democracia desde las aportaciones teóricas de Nussbaum y Morín Diálogos sobre educación. Temas actuales en investigación educativa, 7 (12), pp. 1-18, 2016 Universidad de Guadalajara

Llanos, M. (2009). Resiliencia y género: promotoras comunitarias en Asia y América Latina. Temática Psicológica, 5(5), 35-49

Llanos, M. (2016). Los programas pioneros de educación inicial no escolarizada del Perú y su impacto en la superación de desigualdad educativas de las mujeres. Avances en Psicología, 24(1), 33-49. UNIFE

Fecha de recepción: 15 de setiembre de 2021

Fecha de aceptación: 19 de octubre de 2021
Maire Claire (2020) Por quélas mujeres son las grandes lideres de esta pandemia. https://marieclaire. perfil.com/noticias/sociedad/columna-mujeresen-pandemia-onu-mujeres.phtml

Nussbaum, M. (2011). La crisis silenciosa. Signo y Pensamiento, vol. XXX, núm. 58, pp. 1622. Pontificia Universidad Javeriana Bogotá, Colombia

O Donell. K (1999). Endocalidad. Ediciones Oniro

Ospina, R. (1998). Para Empoderar a las Mujeres Rurales- Ubicación: IICA - misión RuralFINAGRO. Tercer Mundo editores.

Programa mundial de alimentos (2020) Millones en riesgo de inseguridad alimentaria en América Latina y el Caribe.

REAS Red de Redes. España. (2021). Las mujeres de la ESS: informe sobre perfil competencial.

Randi, D. (2021). Betting on Women's Leadership for A Better Tomorrow in a Post COVID World. Source: UNDP

Sau Sánchez, V. (1981). Diccionario ideológico feminista. Icaria

Sau Sánchez, V. (2000). Reflexiones feministas para Principios de siglo

SELA (10 de septiembre 2021) La pandemia retrasaría 10 años la participación laboral de la mujer en A. Latina, según informe de PNU. https://www.sela. org/es/prensa/servicio-informativo/20210910/ si/75762/mujeres

Tabares, L (2021) El trabajo del líder es ser un facilitador. https://www.adlatina.com/publicidad/ laura-tabares:

Vaca, Iliana (2019) Oportunidades y desafíos para la autonomía de las mujeres en el futuro escenario del trabajo. CEPAL.Serie: Asuntos de género. https://repositorio.cepal.org/bitstream/ handle/11362/44408/4/S1801209_es.pdf

Venegas, L y Reverte, I. (2019). La Guerra más larga de la historia, 4000 años de violencia contra las mujeres. Espasa 